\title{
PERSPEKTIF PEREMPUAN MENOPAUSE TERHADAP PEMAHAMAN PIMPINAN TENTANG KEBUTUHAN PEGAWAI PERENPUAN YANG MENOPAUSE : STUDI KUALITATIF
}

\author{
MENOPAUSE WOMEN'S PERSPECTIVE ON LEADERSHIP \\ UNDERSTANDING OF THE NEEDS OF MENOPAUSE AGENCY \\ EMPLOYEES: QUALITATIVE STUDY
}

\section{Ivanna Junamel Manoppo}

Fakultas Keperawatan Universitas Klabat

E-mail: i.manoppo@unklab.ac.id

\begin{abstract}
ABSTRAK
Pendahuluan: Pada usia menopause banyak perempuan masih produktif dalam kegiatan mendukung perekonomian keluarga, tetapi dalam usia yang produktif tersebut banyak perempuan yang menghadapi permasalahan alami yaitu menurunya aktivitas hormone estrogen dan progesterone yang berakibat pada perubahan kondisi fisik dan psikologis yang dapat mempengaruhi kualitas kinerja seseorang. Tujuan: tujuan penelitian adalah untuk mengetahui gambaran gejala, perspektif keinginan perempuan menopause yang bekerja terhadap pimpinan/atasan dan pemerintah. Metode: penelitian mengunakan metode kualitatif dengan wawancara mendalam. Teknik sampling yang digunakan adalah purposive dengan jumlah responden 6 orang. Hasil: pada umumnya para informan mengalami gejala vasomotor (ada rasa kurang enak badan, perasaan badan panas siang dan malam hari, susah tidur, keringat dingin, lemah dan pusing), perubahan kesehatan mental( stress dan depresi), gejala yang berhubungan dengan genitourinaria (sering berkemih dan nyeri), dan mengalami gejala siklus menstruasi yang tidak teratur (jumlah darah yang banyak); Tema perspektif keinginan perempuan menopause terhadap pimpinan yaitu 1) memiliki kesadaran khususnya pengetahuan tentang kondisi dari bawahannya, 2) memiliki keterampilan dalam berkomunikasi dan perilaku, 3) memiliki kebijakan khusus. Diskusi: penelitian bagi pimpinan di institusi atau perusahaan dapat meningkatkan pengetahuan tentang tanda-tanda dan gejala menopause pada bawahannya agar dapat menangani kasus ini dengan baik dalam lingkup pekerjaan.
\end{abstract}

Kata Kunci: manajer/pimpinan, menopause, perempuan bekerja.

\section{ABSTRACT}

Introduction: In menopause many women are still productive in supporting the family economy, but in these productive ages many women face natural problems, namely the decline in estrogen and progesterone hormone activity which results in changes in physical and psychological conditions that can affect the quality of one's performance. Purpose: The purpose of the research is to find out the symptom description, the perspective of the desire of menopausal women who work for leaders / superiors and the government. Method: Research uses qualitative methods with in-depth interviews. The sampling technique used was purposive with the number of respondents 6 people. Results: in general the informants experienced vasomotor symptoms (there was a feeling of unwell, feeling of hot body during the day and night, insomnia, cold sweat, weakness and dizziness), mental health changes (stress and depression), symptoms associated with genitourinary ( frequent urination and pain, and experience symptoms of irregular menstrual cycles (large amounts of blood); The theme of the perspective of the desires of menopausal women toward leaders is 1) having awareness, especially knowledge of the conditions

JURNAL

SKOLASTIK

KEPERAWATAN

Vol, 4, No. 2

Juli - Desember 2018

ISSN: $2443-0935$

E-ISSN 2443 - 16990 
of their subordinates, 2) having communication and behavioral skills, 3) having a specific policy. Discussion: research for leaders in institutions or companies can increase knowledge about menopausal signs and symptoms in their subordinates so that they can handle this case well within the scope of work.

Keywords: manager / leader, menopause, women work.

\section{PENDAHULUAN}

Di Indonesia pada tahun 2000 perempuan yang berusia lebih 50 tahun telah memasuki menopause sebanyak 15,5 juta, diperkirakan pada tahun 2020 perempuan yang berusia lebih 50 tahun telah memasuki menopause sebanyak 30,3 juta5. Ghani (2009) menegaskan bahwa dengan bertambahnya populasi perempuan berusia lebih 50 tahun, berarti bertambah tahun akan makin banyak perempuan yang akan melewati fase menopause di dalam kehidupannya dan harus dipikirkan untuk bisa melalui sebuah kehidupan yang berkualitas dan bermakna. Selain itu perempuan yang berusia lima puluhan itu termasuk kelompok yang bekerja sendiri atau menjadi profesional. Kumalaningsih (2007) menyatakan pada usia tersebut sebenarnya perempuan masih produktif dalam kegiatan " Income Generating" atau mendukung perekonomian keluarga, tetapi dalam usia yang produktif tersebut banyak perempuan yang menghadapi permasalahan alami yaitu menurunya aktivitas hormone estrogen dan progesterone yang berakibat berhentinya haid diikuti dengan berbagai perubahan kondisi fisik dan psikologis seperti kulit keriput, mata kering, vagina kering, insomnia, depresi, pusing ,pendarahan terus-menerus, timbulnya kanker Rahim dan payudara, mudah marah atau tersinggung serta berbagai penyakit degenerative yang lainnya dan bila dibiarkan berkelanjutan akan sangat mengganggu aktivitasnya. Roush (2011) menyatakan menopause digambarkan dalam beberap istilah; perubahan kehidupan, klimakterik, sebuah akhir, permulaan kematian kejayaan wanita. Menopause adalah peristiwa kronologis yang mengingatkan kita bahwa kita bertambah tua dan terjadi perubahan psikologis sehubungan dengan perubahan dalam tubuh kita. Setiap perempuan mengalami pengalaman yang berbeda terhadap menopause, di antaranya akan mengalami perubahan psikologis di mana akan terjadi penuruan dan penyusutan dalam produksi hormone juga organ-organ reproduksi. Para wanita yang bekerja dalam suatu organisasi yang memiliki atasan ataupun manajer yang biasanya mengontrol dan memberi tanggung jawab kepada mereka dalam menjalankan tugas di kantor. Wanita yang mengalami masa menopause mengalami berbagai macam kemunduran fisik yang umumnya disebabkan oleh penurunan hormone estrogen dan progesterone yang dapat mempengaruhi dalam kinerja. Banyak wanita yang berada pada periode menopause mengalami kesulitan untuk menyesuaikan dengan tugas tanggung jawab yang diberikan oleh atasan mereka, dan bukan sedikit yang sering berselisih ataupun atau beradu pendapat dengan atasan dan biasanya dan berakhir 
dengan pengurangan gaji atau diberhentikan dari pekerjaan

\section{BAHAN DAN METODE}

Penelitian ini dilakukan secara kualitatif dengan rancangan studi kasus. Kasus adalah fenomena khusus yang hadir dalam suatu konteks yang terbatasi, meski batas-batas antara fenomena dan konteks tidak sepenuhnya jelas. Kasus itu dapat berupa individu, peran, kelompok kecil, organisasi, komunitas atau bahkan suatu bangsa. Kasus dapat pula berupa keputusan, kebijakan (Poerwandari, 2009)

Subjek partisipan dalam penelitian ini memiliki kriteria sebagai berikut:

1. Berusia $>40$ tahun dan masih aktif bekerja

2. Perempuan perimenopause dan menopause

3. Bersedia dijadikan informan

4. Bekerja sama dan dapat berkomunikasi dengan baik

Populasi dalam penelitian ini adalah perempuan yang berusia $>40$ tahun. Peneliti menggunakan teknik purposive sampling di mana setiap sampel dipilih berdasarkan ketersediaan atas kriteria khusus yang ditetapkan untuk maksud penelitian (Fahmirusydi, 2008). Jumlah informan dalam penelitian sebanyak 6 orang.

Peneliti berfungsi sebagai instrument di dalam penelitian kualitatif, dan sebagai instrument peneliti bisa menangkap interaksi antara peneliti dengan yang diteliti dan interaksi antara fakta dengan konteks penelitian. Membangun hubungan yang baik serta diperlukan kedekatan antara peneliti dengan yang diteliti sehingga peneliti dapat menjelaskan secara rinci bagaimana fenomena yang diamati dengan konteks tempat terjadinya fenomena. Hasilnya kemudian dideskripsikan ke dalam penelitian kualitatif.

Pedoman yang digunakan dalam wawancara mendalam yaitu berbentuk pertanyaan yang bersifat terbuka yang berisi pertanyaan-pertanyaan yang berhubungan dengan 1) apa yang perempuan menopause pikirkan pimpinan dapat lakukan, atau harus lakukan, untuk menolong perempuan menopause yang mengalami kesulitan dalam bekerja sehubungan dengan gejala-gejala menopause; 2) bagaimana pimpinan harus berperilaku, dan 3) bagaimana pimpinan seharusnya tidak berperilaku terhadap perempuan yang sudah menopause. Data yang didapat dapat tersimpan dengan baik dengan cara, merekam semua pembicaraan pada saat wawancara dengan voice recorder dan menggunakan alat tulis serta catatan. Observasi digunakan pada saat wawancara untuk mengetahui ekspresi non verbal dan verbal.

Analisis data adalah proses mengorganisasikan dan mengurutkan data ke dalam pola, kategori, dan satuan uraian dasar sehingga dapat ditemukan tema dan dapat dirumuskan hipotesis kerja seperti yang disarankan oleh data (Moleong, 2009). Pedoman wawancara, tahapannya yaitu:

A. Membuat transkrip, yaitu mencatatat seluruh hasil wawancara dan observasi selama wawancara antara informan dengan peneliti dari hasil catatan dan hasil rekaman

B. Mereduksi data dan membuat koding data, yaitu merangkum, 
memilih hal-hal pokok, mengfokuskan pada hal-hal yang penting dari data mentah. Setelah itu dilakukan koding atau member kode jawaban atau informasi sesuai dengan pertanyaan pada pedoman wawancara atau sesuai dengan informasi yang dibutuhkan

C. Menyajikan data, yaitu menyajikan data yang ditampilkan dalam bentuk uraian singkat atau teks yang bersifat naratif

D. Membuat kesimpulan, yaitu menyimpulkan hasil penyajian data yang masih dalam bentuk narasi atau kutipan langsung dari hasil pembicaraan informan.

\section{HASIL}

Hasil analisis yang telah dilakukan terhadap perspektif perempuan yang bekerja terhadap pimpinan, di dapati beberapa tema di antaranya: gambaran kesulitan bekerja disertai muncul gejala menopause , perspektik keinginan perempuan menopause yang bekerja terhadap pimpinan. Adapun hasil penelitian sebagai berikut:

\section{Gambaran kesulitan bekerja yang dialami perempuan disertai muncul gejala-gejala menopause.}

Enam informan memberikan pengalaman mereka saat mengalami masa perimenopause, menopause dan post menopause, di mana gejala-gejala ini membuat mereka kesulitan saat bekerja. Di antaranya mengalami menstruasi yang sangat banyak, ada rasa kurang enak badan, perasaan badan panas siang dan malam hari, susah tidur , keringat dingin, lemah dan pusing, perubahan siklus menstruasi, nyeri berkencing, mau tidur dan istirahat, sakit kepala, mual, muntah, perasaan takut, sesak napas, gelisah, pusing, rasa malas, rasa capek. Tema yang diambil untuk gambaran kesulitan bekerja ini dihubungkan dengan gejala-gejala menopause. Tema yang diambil pada penelitian ini berhubungan dengan gejala siklus menstruasi, gejala vasomotor, gejala genitourinaria, dan perubahan kesehatan mental. Hal ini dapat dilihat pada penjelasan dan pernyataan berikut ini.

\section{a) Gejala Siklus Menstruasi}

Di antaranya ada responden yang mengalami gangguan siklus menstruasi. Banyaknya jumlah darah yang turun sebelum mengalami menopause. Hal ini menyebabkan informan seringkali ijin karena tidak bisa masuk kantor, karena keluhan perut yang terasa amat sakit dan kondisi badan yang tidak mengijinkan saat itu. Hal ini dapat dilihat pada cuplikan transkrip berikut ini: "kalo masih pre dulu barangkali yah masih di kantor itu (sambil tangan kanan pegang kuping)..eh..(mata melihat ke bawah dan menunjukkkan mimik muka mengingat)eh ..itu ada hambatan karna suka turun banyak (sambil tangan memperagakan) waktu sebelum menopause dulu tapi untungnya pimpinan tidak keras..jadi walaupun tidak bisa masuk kantor karna waktu itu perut teramat sakit dan kondisi badan tidak mengijinkan masuk kantor."

Informan lain menyebutkan sudah mengalami gejala-gejala menopause yang disertai dengan turun haid yang banyak sekali tidak seperti biasanya, kemudian disertai juga dengan siklus haid yang tidak teratur kurang lebih 
sekitar 1 tahun, Kondisi ini berlangsung cukup lama sehingga mempengaruhi kesehatan informan dan menyebabkan kondisi informan lemah, wajah pucat karena Hemoglobin $(\mathrm{Hb})$ rendah dan hal ini menyebabkan informan sempat absent dalam pekerjaan, dan mulai mendapat teguran dari pimpinan.

"Terus itu turun haid yang tidak normal itu dia berlanjut sampe 1 tahun. Ah disitu..sejak itu badan sudah mulai apa, hb sudah mulai turun (intonasi menekankan), hb so mulai turun, wajah so mulai pucat. Berbagai cara sudah dilakukan sudah minum hemaviton (peragakan dengan tangan)yang tambah darah..,karna ini sudah mengganggu kerja kan,sudah mengganggu pekerjaan, nda nyaman.di tempat kerja so lemah,pusing ..yah so mengganggu pekerjaan..ya daripada mengganggu pekerjaan kan (intonasi rendah dan pelan). Waktu itu kerja sudah mulai absent, sudah mulai ada pengeluhan teguran dari pimpinan."

Informan lain didapat ada juga yang mengalami ketidakteratran siklus menstruasi. Hal ini dibuktikan melalui pernyataan informan berikut ini: "setiap menstruasi. pernah ada 1 bulan dua kali dapat, di awal deng di akhir, dalam 1 tahun ada 3 kali"'

b) Gejala-gejala vasomotor

Informan juga menyatakan ada perasaan tidak enak badan yang tidak dapat dijelaskan dengan kata-kata, rasa panas badan siang hari, sehingga hal ini membuat informan tidak nyaman saat bekerja dan harus pulang untuk istirahat di rumah. Kesulitan bekerja yang dialami perempuan menopause dapat dilihat pada pernyataan informan berikut ini: "yah..ada rasa badan kurang enak..nda tau mo diterangkan bagimana (sambil senyum)..iya...ada perasaan (sambil melipatkedua tangan dan menggoyangkan badan)ada perasaan badan itu terasa panas sekali siang..pokoknya suatu perasaan yang nda enak sama skali.sehingga nda bisa..eh..comfotable mo kerja(sambil tangan menunjuk-menunjuk) yah harus ambil waktu untuk pulang menenangkan diri di rumah."

Informan lain menambahkan sejak 6 bulan kejadian siklus haid yang tidak teratur, informan merasakan kesulitan untuk tidur malam hari, waktu siang hari dan malam hari badan terasa panas sehingga rambut menjadi basah dengan keringat. Hal ini dapat dilihat pada cuplikan transkrip berikut ini:

"Dan 6 bulan setelah itu sudah mulai merasakan ada waktu susah tidur malam hari, waktu siang badan seperti panas,malam juga begitu.mau tidur rambut jadi basah (sambil tangan peragakan), basah dengan keringat seperti baru mandi.ah itu..klo begitu kan..apalagik alo orang yang tertutup, nda eh..nda share ke siapasiapa (peragakan dengan tangan) jadi takut."

Informan lain juga merasakan gejalagejala menopause seperti pusing, rasa ingin tidur, hal ini dapat dilihat pada pernyataan berikut ini: "emm..tu gejalagejala lengkali rasa pusing, maunya mo tidur kang (sambil memperagakan dengan kepala ke belakang) mo istirahat, rest dang." 
Informan selanjutnya menyatakan sangat kesulitan ketika menghadapi masa-masa menopause di mana di satu sisi dia dituntut untuk bekerja. Kesulitan yang dihadapi di antaranya: sakit kepala, pusing, mual, muntah seperti orang mengidam. Hal ini dapat dilihat pada pernyataan informan berikut ini:

"kesulitan yang dialami waktu menhadapi masa-masa itu, kita trus bekerja kalo dia sakit kepala ..Cuma 2 kali minta ijin siang karna memang sakit kepala (sambil menunjuk ke kepala). Baru dp fase terakhir itu di akhir-akhir kita memang muntahmuntah, kayak orang ngidam. Jadi mual, muntah (intonasi ditekankan), nda enak tu perasaan."

Ada juga Informan yang memberitahukan gejala-gejala yang dialami saat menjelang menopause saat bekerja seperti vertigo (keadaan di mana penderitanya merasa seolah-olah lingkungan di sekitarnya berputar atau melayang. Kondisi ini juga akan membuat penderitanya kehilangan keseimbangan, sehingga kesulitan untuk sekadar berdiri atau bahkan berjalan), dan kesulitan bernapas. Pernyataan ini dapat dilihat pada cuplikan transkrip sebagai berikut:

"Biasanya sih kita kebanyakan kayak dang vertigo bagitu..kong apa..kalo kadang2 kayak dang $t$ nafas rupa ta brenti Cuma satu. satu. Cuma bagitu noh ...klo dg bekerja biasanya bagitu. kalo siang tidak keringat, malam dingin, sakit kepala itu ada."
Data yang didapat dari Informan lainnya menyatakan membutuhkan usaha yang luar biasa untuk melawan rasa malas yang datang pada saat bekerja disertai juga cepat rasa lelah, tetapi karena pekerjaannya berhubungan dengan melayani orang banyak sehingga harus tetap bekerja. Pernyataan ini dapat dilihat pada cuplikan transkrip sebagai berikut:

"Kalo bekerja sih..karena saya bekerja dengan orang, apakah dia lagi mau bekerja ato nda, tetap harus terlayani, semua tetap harus dilayani. Ada sih rasa malas (sambil senyum), tapi eh..bukan sesuatu yang harus saya buat. Walaupun memang butuh usaha luar biasa sih mo lawan itu rasa malas yang tiba-tiba ato rasa lelah..cuman yah karna..yah itu orang sudah datang musti dilayani."

c) Gejala Genitourinaria

Ada juga informan yang mengalami gangguan pada bagian perkemihan, yang membuat nyeri saat berkemih dan hal ini menyebabkan ketidaknyamanan. Pernyataan ini dapat dilihat pada cuplikan transkrip berikut: "nyeri berkencing sekitar 1 minggu."

d) Perubahan Kesehatan mental

Ada informan juga yang mengalami gangguan secara mental di mana informan merasakan perasaan takut (takut mengambil keputusan, takut melangkah, takut hidup sendiri), perasaan sensitive yang tinggi (kadangkadang tidak bisa diganggu, mudah menangis, mudah tertawa), kadangkadang tidak konsentrasi saat bekerja bahkan sampai ada perasaan depresi 
karena gejala-gejala tersebut sehingga ada saat informan minta ijin untuk tidak masuk bekerja. Pernyataan ini dapat dilihat pada cuplikan transkrip berikut ini: "Rasa takut, pikiran gado-gado, nano-nano samua ada. tinggal sandiri takut, mo melangkah takut, ambe keputusan takut, darah nae turun, (sambil memperagakan dengan tangan) itu noh kita pe pengalaman di tempat kerja. Kan kayaknya kalo mo eh..(mata memandang ke luar jendela sambil mengingat) alami waktu itu..memang kua ta soe dang..memang..memang rasa (sambil menutup mata dan tarik napas) mo mati nyanda mo hidup nyanda, depresi dang."

"kadang-kadang konsentrasi, kadang 2 nda noh.Perasaan takut itu datang, tiba-tiba rasa gerah, tibatiba rasa nano, tiba-tiba rasa nda bisa di ganggu (peragakan dengan tangan) karena boleh dibilang kalo kita pe pengalaman kita sangat sensitive skali. Mudah menangis, mudah tertawa, mudah naik tu darah mudah turun karena torang sensitive."

\section{Bagaimana perspektif perempuan menopause yang bekerja terhadap pimpinan atau atasan}

Informan pada penelitian ini memberikan gambaran perspektif terhadap pimpinan di tempat kerja. Tema yang diambil pada penelitian ini di antaranya: memiliki pengetahuan , keterampilan berkomunikasi dan perilaku, kemudian memiliki usahausaha atau tindakan dari pimpinan. Berikut ini adalah pembahasan dan cuplikan transkrip dari masing-masing informan pribadi-pribadi bawahannya, sehingga dapat memperlakukan mereka dengan baik sesuai kondisi mereka (tahapan usia bawahan) dan tidak disamaratakan dengan bawahan lain yang tidak memiliki keluhan atau mengalami gejala-gejala menopause. Pernyataan ini dapat dilihat pada cuplikan transkrip berikut ini: "jadi kalau saya yang jadi pimpinan (ehmm..batuk sedikit dan mata menatap ke bawah serta tangan memegang telinga) saya kira saya perlu mengetahui eh..keadaan bawahan saya (sambal mata menegaskan) mereka itu ..jenjang umurnya berapa (sambil tangan kiri bergoyang memperagakan) sehingga kalau saat-saat pada waktu mereka tidak bisa masuk karena pengeluhan (sambil tangan memperagakan)saya bisa mengerti keadaan mereka(intonasi rendah). Jadi kalaupun mereka tidak masuk saya mengerti..bahwa mereka tidak masuk bukan karena dibuat-buat tetapi karena keadaan kondisi badan mereka, sehingga saya tidak permasalahkan..(intonasi rendah). yang jadi pimpinan harus punya pengetahuan..iya (mengangguk) khususnya tentang kita puny colleague..kita punya teman sekerja(tangan memperagakan). Jadi, pengetahuan tentang pribadi dari dia."

"Jadi kalau itu di pegawai pemerintah atau di mana mungkin yang kita mo minta adalah supaya pimpinan itu musti mengetahui dia punya..coworkers ini (sambil memperagakan dengan tangan) dorang ini di age berapa so di umur ..Ada berapa banyak so di umur menopose supaya kita mo handle pa dorang mo tangani pa dorang mo treat pa dorang nda sama dengan tu 
yang masih muda-muda yan gmasih energetic iya kan (sambil senyum dan peragakan dengan tangan).jadi eh..supaya katu dorang katu mo masuki masa itu nda ..stress (intonasi ditekandi stress)."

"untuk kita sebagai pimpinan musti ada kebijakan noh itu kan alam itu, dia (pimpinan perempuan) juga akan alami kita kerja dgn ( $m r X)$ mengerti dia, mengerti dia (intonasi ditekan) jadi dia kasih ijin noh. Mengerti dang. Misalnya klo so dirumah kong telepon bilang ..(mr $x)$ dia ngerti noh ini.. (sambil peragakan dengan tangan)."

"Yah kalo mo jadi pimpinan kita komang mengharapkan kalo sebagai seorang pimpinan baik dia laki-laki ato perempuan dorang harus memahami fase-fase di mana dorang pe fase yang paling sulit tu menopause itu.mo pra,mo menuju ke situ sebagai pimpinan dorang musti tau pengalaman perempuan karena banyak laki-laki juga dorang easy going toh nimau tau dorang pe istri da jadi apa dorang pe bawahan perempuan da sementara apa dorang koman nda mengalami. ada juga yang tidak mengalami masa-masa menopause biar dia wanita, dorang juga musti belajar, harus memahami dorang pe bawahan perempuan. Kalo so ada bawahan perempuan yang so aneh-aneh musti cari tau dia sementara apa, karena boleh dibilang kalo kita pe pengalaman kita sangat sensitive skali. Mudah menangis, mudah tertawa, mudah naik tu darah mudah turn. Karena torang sensitive."

1. Keterampilan berkomunikasi dan perilaku
Tema kedua yang muncul dari interview terhadap informan adalah keterampilan pimpinan dalam berkomunikasi dan perilaku. Hal ini digambarkan dalam strategi komunikasi yang diharapkan dan membantu dan juga strategi yang tidak diharapkan dan tidak membantu pada perempuan menopause.

a) Strategi yang diharapkan dan membantu

Wawancara dengan informan ini didapatkan bahwa dalam berkomunikasi seorang pimpinan bisa memberikan kata-kata yang mengandung dukungan (support), kepercayaan serta memberikan semangat dalam melakukan sesuatu sehingga karyawan dapat lebih meningkatkan kinerja dalam pekerjaan. Hasil wawancara ini dapat dilhat dalam transkrip berikut ini: “...supaya...karna kalo diberikan kepercayaan boleh bekerja dengan lebih baik..seperti dalam..(berhenti mengingat) seperti kita dalam berkreasi itu..nah itu..coba be ri..be ri (terbatabata) penghargaan begitu sekecil apapun..kalo diberi penghargaan..eh mungkin kita hanya bisa sampai di dilangkah ke 5 karna dihargai,,kita akan bisa sampai melewati 10 kalo misalnya kita dihargai dang begitu. itu noh seperti tadi saya bilang torang toh mc punya keterbatasan jadi pimpinan harus mengerti saat dia lihat ada yg begitu harus kasih semangat, support trus eh...(berpikir) seperti kepercayaan lah."

Hasil wawancara mendalam dengan informan dikemukakan agar seorang pemimpin harus menjaga kata-kata dan intonasi dalam berkomunikasi (lemah lembut) dan memahami kondisi dari 
perempuan dengan bawahan agar tidak menyinggung perasaan bawahan khususnya perempuan yang mengalami masa transisi menopause karena perasaan mereka sangat sensitive. Hal ini dapat dilihat dalam cuplikan transkrip berikut ini: "kita mudah tersinggung,jadi kalo ada pimpinan misalnya bicara,,mungkin stou katu nda menyinggung tapi karna kita sensitive skali dorang bicara keras kita tersinggung.itu noh tape maksud."

Informan selanjutnya mengatakan bahwa pemimpin itu harus menunjukkan keramahan dalam berkomunikasi dengan bawahan dan bisa datang berbicara dengan pimpinan untuk urusan-urusan pribadi seperti masalah menopause. Bisa dilihat dalam cuplikan transkrip berikut ini: "Pemimpin juga harus tunjukkan ke bawahanmu bahwa you are welcome artinya kasih tau bahwa bawahan itu bisa datang ke saya untuk urusan-urusan yang seperti begitu, yang berkaitan dengan pekerjaan dang you are welcome kalo mo datang."

Informan ini juga menambahkan untuk menjadi seorang pemimpin harus memiliki teknik berkomunikasi mendengar apa yang dibicarakan oleh bawahan dan membantu bawahan dalam mencari solusi atas masalah yang dihadapi. "jadi yang kita harapkan kalo jadi pemimpin dang ba cerita leh noh...artinya dg klo torang bawahan mo pi b cerita dengar akang ..io toh (mimik santai dan senyum) kalo torang bawahan pi ba cerita..mnaksudnya jangan juga..(nada menggantung) cuman eh..dengarkan dulu lah dia ini kenapa sampe terjadi demikian, dan bantuin lah cari solusi." b) Strategi yang tidak diharapkan dan tidak membantu

Berdasarkan hasil wawancara didapatkan informan mengatakan bahwa pemimpin jangan menekan bawahan atau menilai yang tidak baik terhadap bawahan, karena hal ini dapat membawa tekanan dan stress pada bawahan. Hal ini dapat dilihat pada cuplikan transkrip berikut ini: "merasa ada tekanan dari atasan atau dari pimpinan lebih stress lagi.itu akan menambah mereka punya..eh..apa ya..(sambal berpikir) rasa tidak enak itu akan bertambah.saya kira itu."

"dia nimbole itu pa torang (sambil tangan kanan menunjuk ke dada), maksudnya kan dia nimbole tekan torang, dalam posisi itu karna itu alam."

" kalo misalnya saya, kalo so tau salah satu karyawan bagitu yah..jangan terlalu banyak tekan noh..tekanan dalam pekerjaan misalnya ada ..misalnya pekerjaaan yang harus dia buat tapi karena keadaan kondisi tubuh yang lagi tidak stabil jangan tekan noh. Karena torang so pernah alami keadaan sepert itu."

Informan lain menyebutkan bahwa seorang pemimpin itu jangan menghakimi bawahannya, dan dalam berkomunikasi sebaiknya ditanyakan dulu penyebab bawahan itu datang terlambat ke kantor.. Hal ini seperti terlihat pada cuplikan transkrip berikut ini: "misalnya..kalo dia terlambat datang torang menghakimi dia, harus tanya dulu (intonasi di tekan) apa depe masalah, kiapa ngana terlambat datang, 
kiapa ngana bingung-bingung musti cari tau depe latar belakang karna dalam masa menopause bagitu kan aneh2 torang perempuan."

Informan selanjutnya menyebutkan bahwa menjadi seorang pemimpin dalam berkomunikasi diharapkan jangan menggunakan komunikasi yang buruk seperti marah-marah terhadap bawahan, dan jangan sampai putus komunikasi antara atasan dan bawahan, tetapi jika bawahan datang untuk bercerita pimpinan boleh mendengarkan dan mencari solusi yang tepat. "saya rasa jangan marah-marah lah, harus ngobrol begini yang saya lihat ini klo misalnya orang itu sampe dimarah-marahin mungkin komunikasi yang putus.'

2. Usaha-usaha atau tindakan dari pimpinan

Usaha dari pimpinan yang dihubungkan dengan kesulitan perempuan menopause dalam bekerja di antaranya, menginginkan ada kebijakan khusus, serta mengadakan seminar kesehatan agar para karyawan perempuan serta pimpinan mendapat pengetahuan yang benar tentang menopause. Hal ini ditunjukkan dalam cuplikan transkrip berikut ini:

\subsection{Kebijakan yang membantu}

Wawancara dengan informan menyatakan perlu ada cuti khusus bagi yang mengalami haid ekstrim sehubungan dengan masa transisi menopause ataupun ada kebijakan untuk pekerjaannya dapat dikerjakan di rumah. Hal ini dapat dilihat dalam transkrip berikut ini: "eh..mungkin..(smbil mengingat) eh saya dengar juga dari teman yang PNS katanya, kalo di Pegawai negeri itu, tiap bulan ada..ada cuti khusus kalo mengalami datang bulan kang.mungkin ada kebijakan mungkin bisa eh..di eh..terapkan juga bagi mereka yang mengalami eh setiap mengalami datang bulan itu,karna kan, sudah nda seperti dulu normal jadi harus istirahat di rumah, menenangkan diri mungkin biar cuma..selama dia haid 3 hari atau 4 hari ada excuse tapi bisa kerja di rumah..untuk yang mengalami haid ekstrim."

Wawancara terhadap responden yang lain menyebutkan bahwa kebijakan khusus dapat dibuat oleh pimpinan terhadap kasus special seperti menopause, walaupun sudah ada peraturan yang berlaku. "menghadapi masa menopause itu..mungkin ada special eh,eh..apa yah (melihat ke atas).spesial treatment yang kita berikan kepada mereka. tangan)..yah..jadi ada..itu..itu lah kebijaksanaan dari pemimpin walaupun sudah ada peraturan tapi kita harus bijaksana menangani atau melihat kita punya colleague yang seperti ini (sambil memperagakan dengan tangan)."

Informan selanjutnya memberikan pendapat dan saran agar diterapkan Undang-Undang khusus perempuan yaitu cuti haid serta cuti menopause yang dapat dilihat pada transkrip berikut ini: "untuk kita sebagai pimpinan musti ada kebijakan noh itu kan alam itu, dia juga akan alami. Nah kebijakan rupa torang musti kaseh keluar undangundang itu untuk wanita dang, tapi di dalam apa.(sambil tangan berputarputar) di sini (institusi) tidak diterapkan" 
Informan lain menyebutkan agar ada fleksibilitas jam kerja saat menghadapi kesulitan dalam bekerja sehubungan dengan masa transisi menopause, berikut cuplikan transkrip dari informan: "kaseh biarjo kita datang-datang. kalo kita jadi pimpinan kaseh jo kesempatan for dia apa dia mo datang kerja ato mo istirahat sakit."

"kalo kita pe pengalaman bos pe pemahaman tentang kita pe masalah kita mau kita terapkan dang,excusenya..kalo kita lagi sakit jangan datang,kalo kita lagi rasa memang nda bisa maso.ba bilang.ato kalo kita nda suka tinggal di rumah..sama dengan kita pe ungkapan hati kita bilang (pimpinan) jangan larang kua kita datang di kantor.biarjo kua kita datang-datang ato misalnya kita kerja,kita beking cepat-cepat kita pe kerja kong kita pulang cepat mo istirahat diijinkan."

Informan ini juga menambahkan dalam pernyataan bahwa menginginkan diterapkan cuti haid seperti pada pegawai negeri sipil, khususnya yang mengalami pendarahan yang berada pada masa transisi menopause. Keinginan juga ditujukan bagi pegawai honor dapat cuti tanpa dikeluarkan dari pekerjaan karena hal ini dapat memberikan tekanan pada perempuan. Saran juga bagi tenaga indeks ada kebijakan cuti menopause sehubungan dengan penderitaan yang dirasakan saat mengalami gejala-gejala tersebut, tanpa intervensi dari pimpinan sehubungan dengan jumlah hari cuti yang diambil. Hal ini disebabkan gejala pendarahan dapat melebihi jatah cuti bagi karyawan, sehingga dalam hal ini informan menginginkan untuk ada toleransi bagi setiap pimpinan di instansi di mana saja. Pernyataan ini dapat dilihat pada pernyataan informan berikut ini: "io..klo di..pemerintah PNS dang haid saja dorang ada cuti toh, kalo menpause bagaimana kong pas pendarahan depe saran kalo boleh dang cuti tanpa dikeluarkan dari pekerjaan kalo dia honor kang, ato kontrak karena itu kan tekanan toh pikir-pikir kalo maso ulang apa bisa nda diterima."

"kedua bagi torang yang so index kalo torang ada kebijakan untuk dikasih cuti menopause yang supaya torang pe pikiran nda berat, kalo boleh leh torang leh itu harus ada, karena siksa, dan torang alami ini sangat sulit, ta rasa torang ada pengecualian dang, Torang saja kaseh surat dokter kong bisa di ..di kasih cuti dang ada toleransi..kalo boleh.itu cuma saran atau usul for pimpinan ato di mana saja kalo torang bekerja..kalo bisa (dengan nada rendah, dan mimik wajah yang berharap)."

Informan lain memberikan pernyataan bahwa pimpinan dapat memberi ijin serta mendelegasikan tugas dari bawahan yang mengalami sakit karena menopause dan diharapkan juga untuk dapat menerapkan kebijakan seperti di PNS. Hal ini ditunjukkan pada cuplikan transkrip berikut ini: "nyanda harus dang misalnya memang katu deadline bagini tapi karena ada situasi dan kondisi tidak memungkinkan sehingga tidak sesuai dengan jadwal jangan katu torang marah, ato torang anu kalo menurut saya Kalo misalnya kita tau dia banyak pekerjaan kita kurangi sedikit atau di delegasikan ke orang lain" 
"Sewaktu-waktu dang maksudnya ada ijin noh tapi musti dibarengi dengan torang pe policy kurang kage di pemerintah ada kong torang pe policy nyanda bagimana torang. Di harapkan entah dia pegawai negeri ato swasta beking noh Undangundang .karena kalo datang depe pusing kan nimbole kerja. ya secara mc karna pernah alami katu jadi..eh kalo bisa lah torang tau keadaannya, karna torang so pernah alami jadi mgkn ada sokongan kalo dia minta izin sakit, ada excuse noh."

"apa yah..sementara kah ato bagimana ato kita bisa minta tolong depe teman kerja yang lain, tapi kalo nda kita rekrut orang lah..kalo itu akan berlangsung lama"

\subsection{Seminar}

Berdasarkan wawancara yang dilakukan yang dilakukan didapati bahwa seorang pemimpin yang baik harus mengetahui keadaan karyawan yang mengalami gejala-gejala menopause serta bisa mengfasilitasi pengadaan seminar kesehatan yang berhubungan dengan menopause, sehingga para perempuan yang berada di tahap ini ataupun yang akan menuju ke tahap itu sudah dipersiapkan atau dibekali dengan informasi serta pengetahuan tentang halhal tersebut sehingga boleh menjadi lebih siap dan tidak takut apabila gejala tersebut terjadi pada masing-masing individu. Hal ini ditunjukkan dalam cuplikan transkrip sebagai berikut: "mungkin membuat atau mengundang ahli-ahli kesehatan untuk memberikan..(berheti sebentar dan berpikir) eh apa..seminar-seminar tentang gejala-gejala menopause. Trus kepada karyawn yang eh..sebelum dan sementara menghadapi gejala-gejala menopause ini supaya mereka tidak merasa takut."

\section{PEMBAHASAN}

Berdasarkan hasil penelitian maka pembahasan penelitian adalah sebagai berikut:

\section{Gambaran kesulitan bekerja disertai muncul gejala-gejala menopause}

Keenam informan dalam penelitian ini mengalami gejala-gejala yang bervariasi dan mengganggu dalam menghadapi masa menopause di antaranya terjadi perubahan pada siklus menstruasi di mana jumlah darah yang meningkat, kemudian gangguan pada vasomotor yaitu badan terasa tidak nyaman, merasa panas pada tubuh siang hari dan malam hari, susah tidur pada malam hari, keringat banyak, lemah, pusing, vertigo,sakit kepala, rasa malas, rasa capek dan ingin istirahat, stress, dan diikuti oleh perubahan kesehatan mental yang mana menggambarkan perasaan tidak enak (perasaan takut sendiri, takut mengambil keputusan, gelisah); kemudian gangguan pada genitouria: sering buang air kecil dan nyeri berkencing.

Menurut Bacon dalam artikel yang berjudul the menopausal transition (2017) menyatakan bahwa menopause terjadi ketika folikel ovary tidak berfungsi lagi (atau mendekati tahap ini), di mana menunjukkan produksi estradiol berada pada tahap sangat rendah dan dengan jelas terjadi peningkatan FSH (follicle stimulating 
hormone). Gejala-gejala umum dari menopause sering dimulai selama masa transisi perimenopause yang terjadi pada usia 47 tahun atau 4 sampai 6 tahun sebelum terjadi menopause.

Gangguan medis yang sering terjadi disertai proses penuaan menunjukkan beberapa gejala pada orang menopause, perempuan mungkin dapat mengalami kesulitan dalam mengenal apakah mereka memasuki masa transisi menopause. Gejala-gejala terus berlanjut untuk beberapa tahun setelah menopause dan beberapa perempuan mengalami gejala vasomotor untuk periode yang bahkan lebih lama. Kebanyakan perempuan dengan uterus yang masih utuh mengalami menstruasi yang tidak teratur dalam transisi menopause untuk beberapa tahun sebagai akibat dari fluktuasi hormone sebelum terjadi penipisan pada folikel ovary.

Menurut North American Menopause; Rachman; Baziad; Jaszman; Utian dkk dalam Ghani (2009) menyatakan bahwa perubahan fisik yang terasa dan menimbulkan rasa tidak nyaman adalah adanya semburan panas (hot flushes) dari dada ke atas yang sering disusul dengan keringat banyak. Semburan panas ini bisa berlangsung selama beberapa detik sampai I jam. ini merupakan gejala yang paling sering dijumpai. Perubahan dan keluhan lain yang dirasakan lagi seperti berdebardebar (palpitasi), vertigo, migraine, nafsu seks (libido) menurun, gelisah, lekas marah, depresi, susah tidur (insomnia),rasa kekurangan, rasa kesunyian, ketakutan keganasan, tidak sabar lagi, rasa lelah (fatigue), keropos tulang, nyeri tulang belakang, gangguan sirkulasi darah (miokard infark), hipertensi, kenaikan kadar kolestrol darah sehingga terjadi pengerasan pembuluh darah (arteriosclerosis terutama sclerosis koroner), juga berat badan sedikit meningkat karena terjadi adipositas (penimbunan lemak) dan penyebaran lemak terutama ditemukan di tungkai atas, pinggul, perut bagian bawah dan lengan atas. Juga dikatakan pada masa postmenopause ada gangguan pada daerah otak seperti Alzheimer's disease.

Menurut North American Menopause; Rachman; Baziad; Jaszman; Lauritzen; Utian dkk dalam Ghani (2009) Dalam kondisi menopause, dukungan suami atau pasangan dan keluarga sangat penting. Perubahan hormonal itu memang sungguh- sungguh bisa menyebabkan rasa tidak nyaman pada perempuan. Disini ketahanan tiap orang bisa berbeda-beda, ada yang tidak peduli tetapi juga ada yang sangat merasa terganggu.

Dampak menopause dapat terjadi pada siklus menstruasi yang tidak teratur, gejala vasomotor, gejala genitourinaria dan perubahan kesehatan mental.

a. Siklus menstruasi

Perubahan panjang siklus menjadi lebih pendek yaitu 2 hari karena lebih pendek fase folikel produksi FSH. Hal ini juga berpengaruh pada jumlah menstruasi di mana bervariasi jumlah darah dan terjadi bercak darah (spotting) pada periode pertengahan siklus.

b. Gejala vasomotor

Data menunjukkan ada 65-80\% wanita Amerika Utara dan Eropa mengalami hot flashes, keringat sepanjang hari atau malam hari karena menurunya level 
estrogen. Hot flashes (tanda merah di wajah, leher, dan dada saat malu), peningkatan suhu di kulit disertai dengan keringat banyak. Banyak klien mengalami hot flashes pada malam hari dan membuat sulit tidur. Kusmiran (2011) menunjukkan gejala-gejala vasomotor yang lain adalah: sakit kepala, palpitasi, keringat malam, insomnia, hot flashes.

\section{c. Gejala Genitourinari}

Kusmiran 2011 menyatakan vagina terasa kering, nyeri berhubungan sex, vagina terasa gatal atau terbakar, dan frekuensi urine yang meningkat.

\section{d. Perubahan kesehatan mental}

Banyak wanita mengalami peristiwa major dalam kehidupan seperti stress karena perubahan proses keluarga, perceraian, kehidupan janda, perubahan karir termasuk pension. Kehilangan kesuburan klien umumnya berada pada resiko terjadi depresi selama periode ini khususnya yang memiliki pandangan negative terhadap menopause. Wanita pada tahap ini dapat juga mengalami perubahan mood, irritability, lethargy, pelupa, gugup, insomnia dan depresi. Perubahan ini dapat terjadi juga sebagai gejala premenstrual dan juga dapat menjadi gejala-gejala perimenopause.

Gejala-gejala yang mengganggu pada perempuan menopause ditemukan juga pada penelitian dari Griffiths, Maclennan, \& Hassard (2013) di mana gejala yang paling mengganggu saat bekerja yaitu: kurang konsentrasi, kelelahan, daya ingat yang kurang, perasaan depresi/tertekan dan kurangnya percaya diri, terutama Hot flush yang sangat menganggu.

\section{Perspektif keinginan perempuan terhadap pimpinan}

Berdasarkan wawancara mendalam dengan beberapa informan ditemukan beberapa tema di antaranya: 1) yang berhubungan dengan kesadaran pemimpin khususnya pengetahuan tentang kondisi bawahan, 2) hubungan dengan pegawai/keterampilan komunikasi dan perilaku yang diinginkan (pengertian/empati, memberikan dukungan atau kepercayaan kepada bawahan, menyediakan waktu berkomunikasi )atau perilaku yang tidak diinginkan (menghakimi), 3) usaha-usaha atau tindakan pimpinan( seperti membuat seminar untuk meningkatkan pengetahuan dan membuat kebijakan yang mendukung berkaitan dengan ketidakhadiran karena sakit dan jam kerja yang fleksibel, serta pemberian cuti, mendelegasikan dan mendapatkan orang lain untuk melaksanakan tugas.

Menurut Nursalam (2016) ada beberapa kompetensi yang harus dimiliki seorang manajer dalam meningkatkan efektivitas kepemimpinannya pada abad ke- 21. Kompetensi tersebut dikategorikan menjadi tujuh, yaitu: 1) kepemimpinan; 2) pengambilan keputusan dan perencanaan;3) hubungan masyarakat/komunikasi; 4) anggaran; 5) pengembangan; 6) personalitas/perilaku; dan 7) negosiasi.

Hasil penelitian yang dapat dilakukan pimpinan berhubungan dengan kebijakan jika bawahan berada pada masa sulit bekerja sehubungan dengan gejala-gejala yang dialami maka, mereka menginginkan untuk tugas mereka boleh dikurangi atau 
didelegasikan kepada orang lain serta boleh mendapat ijin khusus.

Nursalam (2016) memberikan gambaran kompetensi yang diperlukan dari seorang pemimpin berdasarkan tema yang sudah didapat di antaranya seorang pemimpin dapat mendelegasikan dan mendapatkan orang lain untuk melaksanakan tugas dan menerima tanggung jawab.

Kemudian hasil dari perilaku yang diinginkan di antaranya memberikan dukungan dalam bentuk kepercayaan kepada bawahan untuk mengerjakan sesuatu, di mana hal ini dapat membuat mereka berkarya dengan lebih baik lagi untuk mencapai tujuan seperti yang diinginkan oleh pemimpin.

Hal ini senada dengan Nursalam di mana disebutkan bahwa salah satu prinsip dalam memotivasi kerja pegawai adanya akan prinsip pendelegasian wewenang atau dengan kata lain memberikan kepercayaan dan dukungan di mana pemimpin memberikan otoritas atau wewenang kepada pegawai bawahan untuk dapat mengambil keputusan terhadap pekerjaan yang dilakukannya sewaktuwaktu. Hal ini akan membuat pegawai yang bersangkutan menjadi termotivasi untuk mencapai tujuan yang diharapkan oleh pemimpin.

Lebih lanjut Nursalam menekankan bahwa seorang pemimpin itu harus memiliki hubungan masyarakat/komunikasi yang baik dengan cara menciptakan situasi yang kondusif dalam komunikasi, empati, mendengar, dan tanggap terhadap semua pernyataan orang lain serta mengembangkan proses hubungan yang baik di dalam dan di luar organisasi.

Berdasarkan hasil yang ditemukan diharapkan seorang pemimpin dapat berkomunikasi dengan bawahan disertai dengan kondisi lingkungan yang kondusif. Hal ini didukung oleh Lack (2004) yang mengatakan bahwa menjadi seorang pemimpin itu harus mudah didatangi sekalipun mempunyai kedudukan yang tinggi, dengan kata lain harus menyediakan waktu untuk berkomunikasi dengan bawahannya.

Hal ini didukung oleh penelitian Hardy, Griffiths, Hunter (2017) yang menyatakan bahwa perempuan menopause dapat mengalami kesulitan saat bekerja, dan juga mendapati keinginan perempuan menopause yang bekerja terhadap pimpinan di antaranya; memiliki kesadaran dan pengetahuan terhadap kondisi bawahan, memiliki komunikasi dan perilaku yang baik, kemudian ada usaha tindakan/kebijakan yang dilakukan sehubungan dengan ketidakhadiran perempuan menopause.

\section{KESIMPULAN}

1. Pada umumnya para informan mengalami gejala vasomotor dan yang paling membuat kesulitan dalam bekerja adalah pada masa transisi menopause di mana gejalagejala yang dirasakan sangat mengganggu bagi perempuan yang bekerja

2. Tema :Gejala-gejala yang dialami perempuan menopause yang bekerja di antaranya mengalami gejala siklus menstruasi yang tidak teratur. (gejala vasomotor (ada rasa kurang enak badan, perasaan badan 
panas siang dan malam hari, susah tidur, keringat dingin, lemah dan pusing), perubahan kesehatan mental( stress dan depresi), gejala yang berhubungan dengan genitourinaria

3. Perspektif keinginan perempuan menopause terhadap pimpinan menghasilkan beberapa tema, yaitu seorang pemimpin harus memiliki 1) kesadaran khususnya pengetahuan tentang kondisi dari bawahannya, 2) kemudian diharapkan pemimpin dapat memiliki keterampilan dalam berkomunikasi dan perilaku yang terbagi 2 yaitu strategi yang diharapkan dan membantu serta strategi yang tidak diharapkan dan tidak membantu (strategi yang diharapkan dan membantu dalam berkomunikasi antara pimpinan dan bawahan di antaranya: lemah lembut, memberi dukungan dan semangat, ramah, empati/mau mendengar serta memberikan kepercayaan) sedangkan strategi yang tidak diharapkan dan tidak membantu seperti memberi tekanan terhadap bawahan, dan menghakimi). Tema yang ke-3) usaha-usaha yang dilakukan pimpinan. Ada 2 bagian yang dibahas yaitu; a ) kebijakan pimpinan (memberikan ijin khusus dan mengatur jam kerja yang fleksibel, mendelegasikan tugas serta dapat merekrut orang baru jika keadaan berlangsung lama. pengadaan seminar tentang menopa

\section{SARAN}

1. Kepada pimpinan laki-laki khususnya di sebuah perusahaan ataupun di institusi di mana berada dapat meningkatkan pengetahuan yang berhubungan dengan tandatanda dan gejala menopause pada perempuan ataupun bawahannya agar dapat menangani kasus ini dengan baik dalam lingkup pekerjaan. Selanjutnya pimpinan juga diharapkan memiliki perilaku yang baik dan memiliki keterampilan komunikasi dengan bawahannya.

2. Bagi pimpinan di institusi dapat menerapkan kebijakan dari pemeritntah khususnya cuti haid bagi pegawai dan kebijakan khusus bagi yang mengalami menopause.

3. Kepada pemerintah untuk dapat memberikan atau membuat suatu kebijakan yang mendukung khususnya pada perempuan yang mengalami kesulitan dalam bekerja sehubungan dengan munculnya gejala menopause.

4. Bagi perempuan yang mengalami kesulitan bekerja sehubungan dengan munculnya gejala-gejala menopause, untuk dapat jujur dan terbuka terhadap pimpinan mengenai keadaan yang dihadapi

5. Kepada keluarga khususnya suami dapat memberikan dukungan pada isteri yang memasuki tahap menopause

\section{DAFTAR PUSTAKA}

Bocon J. L. (2017). The menopausal transition. Obstet Gynecol Clin Nort AM.44 (2). 285-296.

Cleaveland Clinic Foundation, 2018 www. My clevelandclinic.org/health/diseas e akses 14 Maret 2018). 
Erbil (2017). Attitude towards Menopause \& Depression, Body Image of Women during Menopause. Alexandria J. Medicine. XXX-XXX.

Ghani, L (2009). Seluk Beluk Menopause. Media Penelitian dan pengembangan Kesehatan, vol. XIX. No.4. 1-5.

Griffiths, A., Maclennan, S.J., \& Hassard, J (2013). Menopause \& work: An electronic survey of employees' attitudes in the UK. J. Maturitas. Vol.76. 155-159.

Hardy, C., Griffith, A \& Hunter, M.s (2017). What do Working Menopausal women want? A qualitative Investigation into women's Perspective on Employer \& Line Manajer Support. J. Maturitas. Vol. 101. 1-8.

Kusmiran, E. (2011) Kesehatan Reproduksi Remaja dan Wanita. Jakarta: Salemba Medika.

Kumalaningsih, S (2007). Sehat dan Bahagia Menjelang dan Saat Menopause. http://books. google.co.id [Diakses 22 Agustus 2017]

Lack (2004). Prinsip-prinsip Kepemimpinan. Jakarta: YASKI.

Moleang, L. (2009). Metodologi Penelitian Kualitatif. Bandung: Rosdakarya. (Fahmirusydi, 2008). (online), (http://hukum.unsrat.ac.id/uu/uu _23_92.htm., diakses tanggal [Diakses 22 Agustus 2017]

Nazarpour, S., Simbar, M., Tehrani, F. (2016) Factors Affecting Sexual Function in Menopause: A review Article. J Obstetrics \& Gynecology. 55. 480-487.

Nursalam (2015). Manajemen Keperawatan. Jakarta: Salemba Medika.

Oshan, S (2008). Maternity, Newborn \& Women's Health Nursing. New York: Mosbys.

Tsing Lo, S \& Ming Kok, W. (2013). Sexuality of Chinese Women around Menopause. J. Maturitas. 74. 190-195. 